Cadernos de Clio, Curitiba, v. 10, $\mathrm{n}^{\circ} .2,2019$

\title{
DIÁLOGO ENTRE ROMANCE E HISTÓRIA: CRIME E CASTIGO COMO CRÍTICA À IDEIA DE PROGRESSO
}

\section{DIALOGUE BETWEEN ROMANCE AND HISTORY: CRIME AND PUNISHMENT AS A CRITICISM OF THE IDEA OF PROGRESS}

Gustavo Pitz ${ }^{1}$

Resumo: A ideia de progresso se fez absolutamente presente no século XIX, principalmente entre as correntes teóricas que pensavam a História. Nesse contexto, são observadas duas características centrais na ciência histórica: primeiro, a recusa da literatura como fonte pelos historiadores; segundo, a tendência historiográfica de entender o progresso como algo unânime e inerente ao século XIX. Sendo assim, o objetivo deste artigo é o de inverter essa lógica: analisar historicamente uma obra literária do século XIX, tendo em vista os aspectos críticos ao progresso nela contidos. Para isso, tem-se como base o romance Crime e Castigo, de Fiódor Dostoiévski, com o intuito de apontar os elementos da narrativa que se constituem como uma crítica político-social à modernidade e suas decorrências na Rússia.

Palavras-chave: Literatura; Crime e Castigo; Progresso; Dostoiévski; Rússia; Crítica.

Abstract: The idea of progress was absolutely present in the nineteenth century, mainly among the History theoretical currents. In this context, two

${ }^{1}$ Estudante do $7^{\circ}$ período do curso de História (Licenciatura e Bacharelado) na Universidade Federal do Paraná. Foi bolsista do Programa Institucional de Bolsas de Iniciação à Docência (2017) e, em 2018 e 2019, foi bolsista no Projeto de Extensão junto ao Museu de Arqueologia e Etnologia da UFPR. Em 2020 foi voluntário no PIBIC na área de História Antiga e, desde então, atua como produtor de conteúdo histórico para o site Turistória. Email para contato: gustavopitz1@gmail.com. Endereço para o Currículo Lattes: http://lattes.cnpq.br/1351303752038658. 
characteristics were observed in historical science: first, the refusal of literature as a source by historians; second, the historiographic tendency to understand progress as something unanimous and inherent in the 19th century. Therefore, the objective of this article is to reverse this logic: to analyze historically a literary work of the 19th century, considering the aspects related to the progress contained therein. For that, it is based on the novel Crime and Punishment, by Fiódor Dostoiévski, in order to point out the elements of the narrative that constitute a social-political critique of modernity and its consequences in Russia.

Keywords: Literature; Crime and Punishment; Progress; Dostoievski; Russia; Criticism.

\section{Sinopse de Crime e Castigo}

Publicado em 1866, Crime e Castigo narra a história do jovem ex-estudante russo Ródia Raskólnikov. Suas ideias de mundo o movem a assassinar duas mulheres na periferia de Petersburgo e, posteriormente, a confessar sua culpa à polícia da região. A narrativa, no geral, se concentra em retratar o sentimento de culpa de Raskólnikov após o crime, junto dos motivos que o levam à autodelação e à superação desse estado de espírito.

\section{Sobre o autor}

Nascido em 30 de outubro de 1821, em Moscou, Fiódor Mikhailovich Dostoiévski foi um dos maiores e mais reconhecidos escritores russos. Ele fez parte da pequena nobreza russa, cujo prestígio e riqueza eram bem inferiores à elite do país. Isso o diferenciou dos demais escritores reconhecidos do seu período, como Tolstoi, Gogol e Turgueniev, uma vez que estes advinham de ordens mais ricas. Antes de completar 20 anos de idade, Dostoiévski já havia perdido sua mãe - vítima de 
tuberculose -, e seu pai - médico assassinado por um de seus servos, pois ao que tudo indica, essa ação foi uma reação à personalidade rígida e intolerante que tinha. Foi nesse período, em 1838, que Dostoiévski ingressou na Escola de Engenharia Militar de São Petersburgo. Sem recursos - situação que permeou toda a sua carreira como escritor -, em 1844 o estudante decidiu seguir a carreira das letras, a partir da escrita de seu primeiro romance, Gente Pobre, seguido por O Duplo e Noites Brancas.

Nesse primeiro momento literário, o autor se caracterizou pela proximidade com o socialismo utópico e a intelligentsia russa, materializada pela sua participação no círculo de Petrashevski. Sob a fachada de estudar literatura e humanidades, alguns membros do grupo incluindo Dostoievski - se dedicavam às discussões revolucionárias, que tangiam principalmente à libertação dos servos e à derrubada do Estado russo czarista. Por conta disso, em 1849 o czar Nicolau I ordenou a prisão de Dostoiévski, acusado de conspiração contra a sua autoridade, e o condenou à morte. Segundos antes da execução, o czar comutou a pena para prisão com trabalhos forçados durante oito anos, na Sibéria, seguido por prestação de serviço como soldado. Esse evento foi crucial para a mudança de perspectiva do escritor sobre a condição humana, intensificada pelo fortalecimento de sua crença no cristianismo ortodoxo (o Novo Testamento era o único livro permitido na prisão).

Em 1860, Dostoiévski retornou a São Petersburgo, e se deparou com uma cidade transformada, palco de uma efusão de ideias filosóficas e 
políticas sobre os rumos do país. Em 1856, a dinastia Romanov assumiu o trono russo, e adotou políticas mais ocidentalizantes, que incluíram a libertação dos servos em 1860 e o estímulo às relações capitalistas. Nesse contexto, em 1864, escreveu Memórias do Subsolo, e dois anos depois, em 1866, publicou Crime e Castigo. Neste ano, acossado por dívidas, o escritor e sua nova esposa, a estenógrafa Anna Grigoriévna, fugiram de seus credores em destino à Europa ocidental, vivendo em cidades como Dresden, Milão, Florença e Genebra. Lá escreveu $O$ idiota (1868) e $O$ eterno marido (1870).

Depois disso, Dostoiévski voltou a São Petersburgo e deu continuidade a sua segunda fase literária, iniciada com Memórias do Subsolo. Já mais reconhecido profissionalmente nesse período, o autor aumentou a produtividade de seu trabalho, do qual resultaram as publicações de Os demônios (1871), O adolescente (1875) e Os irmãos Karamazov (1878), além da edição do Diário de um escritor, que se iniciou em 1873 e se estendeu até 1881. Em 28 de janeiro de 1881, depois de ter perdido o seu filho Aleksiéi, Dostoiévski faleceu, deixando vários projetos inconclusos, inclusive a continuação de Os irmãos Karamazov.

\section{Contexto da obra}

Em 1855, Alexandre II ascendeu ao poder do Império Russo. De forma diferente de seu antecessor, Nicolau II - que adotou políticas mais repressivas -, Alexandre II caracterizou-se por implementar um governo mais reformista e modernizador. Ele foi responsável pela libertação dos 
servos, em 1860, após décadas de contestação da intelligentsia russa e dos revolucionários contra o regime de servidão. Logo, construiu-se no país uma imensa rede de telégrafos acompanhada de uma nascente indústria de ferro. Em consequência, iniciaram-se, na década de 60, os movimentos grevistas dos trabalhadores, de forma a assinalar essa nova fase russa de paulatina industrialização e urbanização (HOBSBAWM, 1977: 126). Além disso, os primeiros anos de Alexandre "foram marcados por uma liberação significativa da cultura, por nova abertura na discussão pública e por grande fermento de expectativas e esperanças" (BERMAN, 1986: 203). São Petersburgo, principal cidade do país, assim se tornou palco de discussões políticas e filosóficas sobre aquele presente.

Entretanto, conforme Berman, os novos intelectuais que surgiam nesse contexto, oriundos de diversos estratos sociais, os raznochintsy, confrontaram-se com uma realidade que, embora aparentemente modernizadora, mantinha uma estrutura tradicional. Alguns destes, sobretudo, questionavam a contradição existente entre as incorporações das ideias da burguesia ocidental pelo Estado e a intelligentsia - como a concepção de progresso e o utilitarismo capitalista - e a manutenção da estratificação social e da marginalização dos pobres (BERMAN, 1986: 203). Como resposta, muitos integrantes da nova geração passaram a evidenciar pela literatura, por exemplo, essa conjuntura, opondo-se à incorporação de ideias ocidentais. Sobre isso, Turgueniev, em Fumaça (1866), assinalou: "Progresso? Progresso seria Petersburgo queimar por inteira!” (BERMAN, 1986: 219). No mesmo ano, Dostoiévski, em Crime e 
Castigo, seguiu essa linha crítica supramencionada, sendo por esse motivo o objeto de estudo do presente artigo.

Essa crítica romântica dostoievskiana não se iniciou em 1866. Alguns anos antes de começar a escrever Crime e Castigo, em 1862, Dostoiévski viajou à Inglaterra e à França e vivenciou os efeitos do capitalismo industrial. Em Notas de inverno sobre a impressão do verão, de 1863, o autor fez uma reflexão sobre o que ele vira no ano anterior, produzindo uma imagem do capitalismo europeu quase totalmente negativa (BEZERRA, 2001: 10). Logo, Crime e Castigo seria o resultado desse caminho de reflexão filosófica, solidamente construído através da experiência em locais nos quais a sociedade burguesa havia se desenvolvido e numa Rússia que parecia seguir o mesmo modelo social capitalista (BEZERRA, 2001: 11). Nesse sentido, a crítica de Dostoiévski foi, sobretudo, uma insatisfação do autor russo ao que poderia se tornar a Rússia caso mantivesse as políticas ocidentalizantes.

\section{A crítica à ideia de progresso}

A própria arte Dostoiévski chamava de "realismo superior". Isso porque, segundo ele, a realidade a qual retratava não era somente a material e visível, mas também a espiritual, as ideias, a subjetividade, a consciência (PAREYSON, 2012: 9). A partir disso, em Crime e Castigo, Dostoiévski, pela ferramenta da polifonia, resgatou toda aquela efusão de ideias filosóficas e políticas da década de 1860, deslocou-as para o romance e as personalizou: cada personagem é um ideólogo, detentor de uma ideia 
filosófica específica sobre o mundo. "A multiplicidade de vozes e consciências independentes e imiscíveis e a autêntica polifonia de vozes plenivalentes constituem, de fato, a peculiaridade fundamental dos romances de Dostoiévski” (BAKHTIN, 1981: 2). Ateus, cristãos, reacionários, revolucionários, capitalistas, assassinos, libertinos, etc., todos aparecem na obra e defendem as suas visões de mundo. E, o herói dostoievskiano, neste caso Raskólnikov, é o principal dentre todas as ideias.

Dessa forma, a centralidade no romance não é dada aos acontecimentos nele presentes, mas ao embate entre diferentes ideias sobre um mesmo problema. Para cada concepção ou personagem - com enfoque no herói -, Dostoiévski determinou um destino, como se a crença em certos valores demarcasse o papel de cada qual na sociedade (PAREYSON, 2012: 35). A partir disso, pretendo analisar as principais personagens de Crime e Castigo e quais foram os seus destinos mediante o resgate de algumas partes do livro que satisfaçam essa abordagem.

O cenário do romance é a São Petersburgo dos anos de 1860. Dostoiévski narrou o clima sufocante e poluído da região, repleta de tavernas, bordéis, bêbados errantes e gente pobre pedindo esmola. Ródia Raskólnikov, personagem principal e esmagado pela pobreza, vivia num cubículo claustrofóbico, devia o aluguel do imóvel e penhorava todos os seus objetos com uma velha da região. $\mathrm{O}$ trancamento do curso de Direito por Raskólnikov, vide o contexto, foi uma mera consequência da pobreza do jovem estudante. Sem projeção de futuro, numa cidade que parecia 
acabar com qualquer perspectiva de melhora, Ródia perambulava e divagava, tentando imaginar possíveis saídas.

Raskólnikov, como ideólogo, postulava a seguinte filosofia:

É só na minha ideia central que eu acredito. Ela consiste precisamente em que os indivíduos, por lei da natureza, dividem-se geralmente em duas categorias: uma inferior (a dos ordinários), isto é, por assim dizer, o material que serve unicamente para criar seus semelhantes; e propriamente os indivíduos, ou seja, os dotados de dom ou talento para dizer em seu meio a palavra nova. [...] Em linhas gerais, formam a primeira categoria as pessoas conservadoras por natureza, corretas, que vivem na obediência e gostam de ser obedientes. [...] Formam a segunda categoria todos os que infringem a lei, os destruidores ou inclinados a isso, a julgar por suas capacidades. Os crimes desses indivíduos, naturalmente, são relativos e muito diversos; em sua maioria, eles exigem, em declarações bastante variadas, a destruição do presente em nome do futuro (DOSTOIÉVSKI, 2001: 269-270).

A esses que infringem, Raskólnikov chama de extraordinários. $\mathrm{O}$ grande nome dessa categoria, para ele, era Napoleão Bonaparte, “o verdadeiro soberano, a quem tudo é permitido, esmaga Toulon, faz uma carnificina em Paris, esquece um exército no Egito, sacrifica meio milhão de homens na campanha da Rússia [...] e ao morrer é transformado em ídolo" (DOSTOIÉVSKI, 2001: 283-284). Esses seriam os heróis hegelianos, aqueles que captam a marcha do progresso e a aceleram, que rompem com os limites de cada fase da evolução humana em nome do novo. É, portanto, papel destes realizarem a Ideia no tempo, através da 
quebra do colete de força que tenta contê-los (HARTMAN, 1990: 36-37). Raskólnikov, assim, retoma a ideia de progresso e a dialética da formação do Espírito, de autoria de Hegel, e atribui a sua materialização aos heróis, justificando essa teoria pela existência de supostas leis da natureza. Raskólnikov é, sobretudo, um hegeliano (FABRIS, 2005: 9).

É a partir dessa teoria que Ródia tentará superar a sua condição social. Até então, ele era um ordinário, que vivia à margem da sociedade pela falta de recursos. Estava cansado de esperar a felicidade geral prometida pelos socialistas, e quis provar para si que poderia fazer parte da segunda categoria e transgredir os limites que a ele estavam sendo impostos. A ideia foi matar Aliena Ivánovna, penhorista que se aproveitava da pobreza de seus clientes, inclusive de Raskólnikov, para enriquecer. Acreditava que, fazendo isso, ele provaria a sua capacidade extraordinária. O fato ocorreu: ele não só a matou, como também assassinou sua filha, Lisavieta, que infortunadamente chegou à casa da velha na hora do crime. Conforme Ródia justifica, "não foi para ajudar minha mãe que eu matei isso é um absurdo! Eu não a matei para obter recursos e poder, para me tornar um benfeitor da humanidade. [...] Eu simplesmente a matei, matei para mim, só para mim" (DOSTOIÉVSKI, 2001: 427). Foi a tentativa daquele relegado ao esquecimento provar para si que poderia fazer parte da história, do progresso, afirmando a incapacidade do mundo e de sua condição social de impedi-lo.

Além de Raskólnikov, outro personagem ganha grande destaque na obra, mas como vilão. Piotr Pietróvitch Lújin era juiz de instrução, homem 
de negócios, que se portava de acordo com os padrões burgueses da Europa Ocidental. Pretendia pedir em noivado a irmã de Raskólnikov, Avdótia Románova, e para isso foi buscar aprovação do futuro cunhado. Nos embates travados entre ambos, fica claro o ideal utilitarista e burguês de Lújin. Ele se diz integrante da "nova geração", concatenado às ideias de progresso. Segundo ele:

Já diz a ciência: ama acima de tudo a ti mesmo, porque tudo no mundo está fundado no interesse pessoal. Se amas apenas a ti mesmo, realizas os teus negócios de forma adequada e ficas com o cafetã inteiro. Já a verdade econômica acrescenta que quanto mais negócios privados organizados houver numa sociedade e, por assim dizer, cafetãs inteiros, tanto mais sólidos serão seus fundamentos e tanto mais organizada será a causa comum. Logo, ao adquirir única e exclusivamente para mim, precisamente dessa forma eu adquiro como que para todos e levo a que o próximo receba um cafetã um tanto mais rasgado porém não mais de favores privados isolados e sim como resultado do avanço geral (DOSTOIÉVSKI, 2001: 167).

Como se pode observar, Lújin mostra-se um ideólogo das postulações do utilitarismo iluminista, mais precisamente de Jeremy Bentham. Em Uma Introdução aos Princípios da Moral e da Legislação, Bentham se ancora na concepção segundo a qual a utilidade é a propriedade que leva ao benefício e à felicidade individual. Assim como Lújin, para o economista a soma das ambições e interesses individuais, em prol da utilidade, levaria à felicidade comum e à resolução dos problemas sociais (LEÃO; PEDROSO, 2014: 154). Em qualquer situação no decorrer da 
narrativa, este personagem tenta tirar proveito econômico frente aos demais, persuadindo, enganando e usurpando.

A ironia ao socialismo utópico quanto à irrealização da felicidade geral, feita por Raskólnikov, persiste na representação do personagem Andriêi Liebeziátnikov. Este, ex-aluno de Lújin, era declaradamente apoiador das ideias de Charles Fourier. Como ideólogo do socialismo utópico, diz o narrador,

aderia ao progresso e às "nossas novas gerações" por paixão. Era um dentre a legião inumerável e variegada de tipos vulgares, de abortos macilentos e tiranetes ignorantes, que num fechar de olhos aderem forçosamente à ideia mais em voga para banalizá-la no mesmo instante, caricaturar de imediato tudo a que homens mesmo às vezes servem de forma mais sincera (DOSTOIÉVSKI, 2001: 374).

$\mathrm{O}$ autor destacou também que era do interesse do personagem contribuir para a construção de uma futura comuna, aos moldes da doutrina de Fourier e do proposto pelo romance de Tchernichevski Que fazer?. Conforme pode ser observado, Dostoiévski produziu uma representação crítica do socialismo, opondo-se a essa teoria.

$\mathrm{Na}$ obra também houve espaço para a representação de grupos sociais mais abastados, como os proprietários de terra, cuja ética Dostoiévski questiona. Ela se dá por Svidrigáilov. Era ex-soldado, homem rico do interior, libertino, aproveitador e ocioso, e durante a obra admite a prática de açoite em servos e violência contra mulheres. Todas as suas obras de caridade aparecem no romance como uma tentativa de disfarçar 
essa sua personalidade. O único aspecto menos ofensivo referido a ele se dá quando Svidrigáilov traz a nova configuração de Petersburgo após 1860. Para ele, "o povo enche a cara, os jovens instruídos, por falta do que fazer, levam a vida em sonhos irrealizáveis e devaneios, e deformam as mentes em teorias" (DOSTOIÉVSKI, 2001: 489). Não é por acaso que ele se diz leitor do autor romântico Friedrich Schiller, com o qual partilhava, como pode ser visto, uma repulsa às ideias que sustentavam a sociedade burguesa. De qualquer forma, a representação dos atores sociais ligados ao tradicional regime de servidão, com exceção a esse aspecto, é expressivamente negativa.

No romance, o contraponto a todas essas ideias é personificado pelo melhor amigo de Raskólnikov, Razumíkhin, e pelas mulheres jovens, Sônia Ivánova - prostituta que possuía um forte afeto por Ródia - e Avdótia. Razum deriva de razão, juízo ou intelecto, aspecto que indica qual é o papel desempenhado por Razumíkhin. Para ele, "todos nós, no que se refere à ciência, ao desenvolvimento, à razão, à experiência e tudo, tudo, tudo, tudo, ainda estamos na primeira classe preparatória do colégio! Nós nos contentamos em viver da inteligência alheia - e nos impregnamos!" (DOSTOIÉVSKI, 2001: 214). Ele, mesmo sendo estudante de direito, recusa as filosofias e a ciência, tensiona a incorporação das ideias ocidentais em solo russo. Embora muito inteligente, a grande virtude apresentada ao longo da obra é sua fidelidade ao amigo, mesmo nos momentos em que este se distanciou das afetividades, e seu caráter nacionalista. Em virtude disso, Razumíkhin é representado positivamente 
em toda a narrativa, como se fosse o exemplo a ser seguido pelos demais personagens.

Além dele, as mulheres jovens ganham fundamental importância, o que mostra um outro aspecto significativo desta obra dostoievskiana. Representadas por Sônia e Avdótia, recusam os autoproclamados homens do progresso, e constroem uma própria ideologia de oposição. Por exemplo, Avdótia, irmã de Raskólnikov, rechaça propostas de casamento - primeiro a de Lújin e depois a de Svidrigáilov -, devido ao caráter de ambos, e estabelece união precisamente com Razumíkhin. De outra maneira, Sônia força Ródia a se confessar, pois não conseguia permanecer junto a um homem preso a teorias filosóficas que feriam a ética cristã, como o amor ao próximo. Ao mesmo tempo, é ela quem ajuda Raskólnikov a superar a sua síndrome de inferioridade, através do reforço da fé em contraponto à ciência. Ambas são religiosas e trilham um caminho digno de vida que foge à lógica ocidental.

Feita a representação desses personagens, atentarei agora ao destino que estes tiveram na obra. Lújin, primeiramente, foi o mais detratado. Sua ambição de se casar com Avdótia Románova foi interrompida por ela. Avdótia, com o tempo, percebeu o caráter desencantado, frio e utilitarista de Lújin, algo que a fez determinar o fim do noivado. Não obstante, durante a celebração fúnebre pela morte de Marmieládov, o qual foi bancado pelo amigo Raskólnikov, Lújin tenta se vingar dessa recusa. A tentativa caiu por terra quando Andriêi revelou no cortejo os objetivos de Lújin, fazendo com que todos expulsassem o juiz de instrução. Dessa maneira, Dostoiévski 
critica o utilitarismo em dois sentidos: o primeiro deles diz respeito à impossibilidade de sentimentos de humanidade que esta ideia representa, pois não é capaz de amar; o segundo, a como demonstrou que esses novos capitalistas não respeitavam sequer os momentos de espiritualidade, na medida em que tentavam tirar proveito inclusive das situações relacionadas à religião. Por conseguinte, Lújin não reaparece na obra, pois é marginalizado pelos demais personagens, como se esta filosofia não tivesse mais espaço entre eles.

De maneira semelhante Svidrigáilov é descrito no romance. Após novas tentativas de comprar o casamento com Avdótia, essa lhe dá um tiro como forma de decretar a impossibilidade do matrimônio e da permanência do nobre na narrativa. Num primeiro momento, Svidrigáilov não falece, entretanto, logo em seguida, ele mesmo se apropria da arma e se suicida. Nesse sentido, a mensagem passada por Dostoiévski parece ser que, no mundo das novas ideias, os estamentos tradicionais da Rússia não têm espaço, assim como suas práticas de violência, corrupção, libertinagem e pedofilia. Isso não significa, todavia, que "as novas gerações" possuam ideal que supere esses problemas da antiga classe nobiliárquica; muito pelo contrário, como pode ser visto por Lújin, o novo se diz diferente, mas mantém determinadas características passadas e acentua outras, como o desencantamento do mundo pela banalização da religião e o individualismo, algo que nem mesmo a elite tradicional possuía.

A grande crítica se concentra na representação do próprio herói do romance. Após cometer o crime, Raskólnikov esperava não se sentir 
afetado pelo ato. Segundo ele, os extraordinários não se abalam frente às suas ações; suas preocupações, pelo contrário, se concentram na realização do novo, em seu impacto no futuro. Porém, não foi isso o que aconteceu. $\mathrm{O}$ que se seguiu foi o surgimento de um forte sentimento de impotência e decepção. Isso, pois, segundo ele,

matei apenas um piolho, inútil, nojento, nocivo. [...] Naquela ocasião [o crime] eu precisava saber, e saber o quanto antes: eu sou um piolho, como todos, ou um homem? Eu posso ultrapassar ou não! [...] Foi a mim que eu matei, não a velhota. No final das contas eu matei simultaneamente a mim mesmo, para sempre! (DOSTOIÉVSKI, 2001: 425-428).

Raskólnikov não se sentia culpado necessariamente pelo crime. Ele ficou arrasado pois sua atitude não era significativa para a História como foram as de Napoleão, ao mesmo tempo em que sua reação ao acontecido não foi de indiferença, como deveria ser a dos extraordinários. Ao ultrapassar os limites da moral, conforme a concepção do personagem, suas preocupações se centraram somente nas consequências que aquilo traria para ele, inclusive numa possível prisão. Devido a isso, Ródia passou a se ver como um "piolho", como alguém fadado à categoria de ordinário, que não possui os predicados necessários para ser diferente e se tornar o herói da História. Isso o afastou de todas as relações afetivas que possuía, inclusive com a própria família e amigos. Raskólnikov passou a não amar mais, pois tinha vergonha de si. Foi essa consciência oprimida do herói que contribuiu para que ele confessasse sua culpa junto à polícia da região; não 
por se sentir arrependido, mas por aceitar as consequências de ser um homem ordinário.

Por meio do juiz Porfírí, que ordena a prisão de Raskólnikov após a sua autodelação, a possibilidade de superação desse estado de espírito se deu nas seguintes palavras: "O senhor, em primeiro lugar, está precisando mudar de ares há muito tempo. Bem, o sofrimento também é uma boa coisa. [...] Sei que não acredita - mas o senhor pare com esse jeito finório de filosofar, entregue-se à vida de forma direta, sem discutir" (DOSTOIÉVSKI, 2001: 469). Desse modo, Dostoiévski tenta demonstrar que as filosofias do mundo acorrentam o sujeito em uma realidade muito distante da vida, das relações humanas, ao ponto de naturalizar mortes para atingir os princípios estabelecidos (PAREYSON, 2012: 42).

\section{Idealização da religiosidade}

É pela figura de Sônia que a libertação do personagem para a vida acontece. Ela o apresenta e lê o Novo Testamento, na passagem da ressurreição de Lázaro. A moral da história explica que a dignidade, aceitação do sofrimento, leva os fiéis ao paraíso, ou até à ressurreição, como no caso de Lázaro. Na prisão, na qual é condenado a oito anos de trabalhos forçados, Ródia mantém contato com o Novo Testamento, único livro liberado aos presos. Isso reforça nele as palavras bíblicas, fazendo-o acreditar que mesmo os marginalizados, como ele, poderiam ser exaltados. "Ele ressuscitara, e o sabia, sentia todo o seu ser plenamente renovado. [...] A dialética dera lugar à vida, e na consciência devia elaborar-se algo 
inteiramente diferente" (DOSTOIÉVSKI, 2001: 559). Aqui, Raskólnikov volta a amar e a valorizar suas relações afetivas, liberta-se das amarras da ciência para aproveitar a integridade da religião como sendo a única que pode fazer renascer os indivíduos imersos na escuridão das ideias racionais.

É somente no Epílogo, momento que retrata essa passagem da prisão, que Ródia, deixando de pensar no futuro, se volta à idealização de determinado passado.

Lá, na estepe sem fim banhada de sol, negrejavam tendas de
nômades como pontinhos que mal se distinguiam. Ali havia
liberdade e vivia outra gente, em nada parecida à de cá, lá era
como se o próprio tempo houvesse parado, como se ainda não
tivesse passado o século de Abraão e o seu rebanho
(DOSTOIÉVSKI, 2001: 558).

Raskólnikov desejava a volta da sociedade agrária russa, de um tempo no qual a religião cristã ortodoxa prevalecia e a simplicidade da vida era a maior preciosidade. Distante da racionalidade e do espírito utilitarista, viver-se-ia de maneira plena.

Entendendo o romantismo segundo Löwy e Sayre, que o definem como uma visão de mundo que "representa uma crítica da modernidade, isto é, da civilização capitalista, em nome de valores e ideia do passado" (LÖWY; SAYRE, 2015: 39), é fundamentalmente nesse ponto, no final do romance, que se delineou o Dostoiévski romântico. Ao criticar o utilitarismo pela representação caricatural do magistrado Lújin, assumidamente capitalista, e imputar ao hegelianismo de Raskólnikov o 
motivo pelo qual ele ficou cismado e desumano, vê-se que o autor russo combateu as duas principais ideias sobre as quais se sustentava a sociedade burguesa, e que estavam sendo incorporadas tanto pela intelligentsia russa quanto por parte das novas gerações de intelectuais no período.

Devido a isso, é comum classificar Dostoiévski como um revolucionário anti-capitalista. Porém, o autor também se opôs aos socialistas utópicos, como Andriêi, uma vez que o socialismo, além de uma teoria ocidental, também não rompia com o ideal de progresso. O que se pode inferir, entretanto, é a proximidade do romancista com o pensamento romântico não-revolucionário do século XIX, e principalmente com o nacionalismo. Conforme visto na representação de Razumíkhin, grande importância é dada a esse personagem, essencialmente no que tange a sua crítica à apropriação das ideias ocidentais na Rússia. Em relação às mulheres, embora de forma menos enfática, Dostoiévski procede de forma semelhante. De certa forma, isso indica o posicionamento do autor, o que incluiu suas críticas e aspirações de mundo.

Nessa perspectiva, através de Crime e Castigo, Dostoiévski denunciou os perigos que representavam essa nova fase da Rússia e a crença no progresso, algo que poderia naturalizar no país a violência e banalizar a religião. O progresso e a modernidade, para ele, legitimavam guerras, crimes, e acabavam com qualquer forma de relação humana e afetiva. Isso não significa, entretanto, que o escritor defendia a volta da supremacia da nobreza russa; muito pelo contrário, observa-se pela representação de Svidrigáilov que os abastados nada tinham de 
positividade. Por isso, o tempo idealizado no romance é anterior ao do estabelecimento das relações de servidão; é um tempo praticamente bíblico, sem limites temporais estabelecidos por ele. Nesse sentido, dentro das tipologias de romantismo estabelecidas por Löwy e Sayre, podemos enquadrar Crime e Castigo como produto de uma visão romântica resignada, que se define por um desejo de restituição, isto é, de restauração ou recriação de um passado, o qual é objeto de nostalgia (LÖWY; SAYRE, 2015: 87). Visto a falta de descrição desse passado, não dá para afirmar que se refere ao medieval - comum entre os eslavófilos russos, como Dostoiévski -, mas os aspectos de uma sociedade rural e profundamente assentada sobre a religião são vigorosamente ressaltados.

\section{Considerações parciais}

Através do romance, observa-se um Dostoiévski que contestou o capitalismo e o progresso, que não aceitou a modernidade ocidental em solo russo, e que exprimiu por meio da literatura, principalmente em Crime e Castigo, toda a sua crítica ao contexto no qual estava inserido. Isso denota o valor histórico do romance pois, além de tentar compreender um mundo que a historiografia negligenciava, ele se constituiu sendo contra o progresso mesmo no século XIX. Talvez a grande perspicácia de Dostoiévski seja a de apresentar todas essas ideias ocidentais e o contraponto a elas de forma personalizada. Isso permitiu não só apontar o posicionamento do autor, como também adentrar no contexto da história e captar as diferentes ideias e compreensões de mundo. 


\section{Referências}

BAKHTIN, Mikhail. Problemas da poética de Dostoiévski. Rio de Janeiro: Forense-Universitária, 1981.

BERMAN, Marshall. Tudo que é sólido se desmancha no ar: A aventura da modernidade. São Paulo: Companhia das Letras, 1986.

BEZERRA, Paulo. Prefácio. In: DOSTOIÉVSKI, F. M. Crime e Castigo. São Paulo: Editora 34, 2001.

DOSTOIÉVSKI, Fiódor. Crime e Castigo. Tradução de Paulo Bezerra. São Paulo: Editora 34, 2001.

FABRIS, Leonardo Prates. Criminologia em Dostoiévski: "Crime e Castigo" como crítica à racionalidade clássica. 2005. 37 f. Monografia (Especialização em Ciências Jurídicas) - Pontifícia Universidade Católica do Rio Grande do Sul, Porto Alegre, 2005. Disponível em: $<$ http://conteudo.pucrs.br/wp-content/uploads/sites/11/2018/09/leonardo_fa bris.pdf>. Acesso em: 04 maio 2019.

FARIA, Daniel. Quando os poetas se despediram da felicidade: Baudelaire e Dostoiévski criticam as utopias. História: Questões \& Debates, Curitiba, n. 44, p. $69-86,2005$.

FRANK, Joseph. Os anos milagrosos: 1865-1871. In: Dostoiévski: um escritor de seu tempo. São Paulo: Companhia das Letras, 2018, ebook.

HARTMAN, Robert S. Introdução. In: HEGEL, Georg Wilhelm Friedrich. A Razão na história: uma introdução geral à filosofia da história. São Paulo: Moraes, 1990.

HOBSBAWM, Eric. Era do Capital. São Paulo: Paz e Terra, 1977.

JONES, Malcolm V. Some Echoes of Hegel in Dostoyevsky. Slavonic and East European Review, Londres, v. 49, n. 117, p. 500-520, 1971. 
Disponível

em:

$<$ http://www.jstor.org/stable/4206449?seq=1\#page_scan_tab_contents $>$. Acesso em: 01 maio 2019.

LEÃO, Igor Z. C. C.; PEDROSO, Ednilson R. O utilitarismo e a crítica de Dostoiévski. Rev. Let., São Paulo, v. 54, n .1, p. 151-165, 2014. Disponível em: $\quad<$ https://periodicos.fclar.unesp.br/letras/article/download/6328/5378>. Acesso em: 02 maio 2019.

LÖWY, Michael; SAYRE, Robert. Revolta e melancolia. São Paulo: Boitempo, 2015.

PAREYSON, Luigi. Dostoiévski: Filosofia, Romance e a experiência religiosa. São Paulo: Edusp, 2012.

Recebido em: 18/08/2019 Aceito em: 06/02/2021 